\title{
Colômbia, Brasil e Venezuela e os impactos no mercado de trabalho
}

\author{
MARIANA HANSEN GARCIA ${ }^{I}$ \\ e CÁSSIO DA SILVA CALVETE ${ }^{I I}$
}

\section{Introdução}

$\mathrm{O}$ S ANOS 1990 na América Latina foram marcados por altas taxas de desemprego e por um processo de precarização do trabalho. Em parte, essa deterioração do mercado de trabalho pode ser explicada pela implementação, naquele momento, de políticas de cunho neoliberal em quase todos os países latino-americanos. No início do século XXI, alguns desses países alteraram sua política econômica com a ascensão de governos de centro-esquerda e de esquerda. Concomitantemente, houve melhora generalizada nos indicadores de emprego.

Para efeito de comparação agrupamos as principais economias latino-americanas em três blocos de países com base em estudos de Iglecias, Cardoso e Streich (2014), Toledo e Neffa (2010) e Elicabide (2013):

a) países em que o governo buscou restringir as politicas neoliberais e amenizar os seus efeitos no mercado de trabalho (entre eles Brasil, Uruguai e Argentina);

b) países nos quais o governo aprofundou o modelo neoliberal (entre eles Colômbia e México);

c) países com governos criticos ao capitalismo que buscaram uma ruptura completa com o modelo neoliberal (entre eles Venezuela, Bolívia, Equador).

O objetivo principal deste estudo é compreender a relação entre as diferentes estratégias de desenvolvimento em disputa no início do século XXI e as mudanças no mercado de trabalho na América Latina. Para observar essa relação comparamos as mudanças no mercado de trabalho do Brasil, da Colômbia e da Venezuela, como exemplo dessas diferentes políticas que vigoraram nos países latino-americanos. Para avaliar o mercado de trabalho foram consideradas as seguintes variáveis: taxa de desemprego, informalidade ${ }^{1}$ e remuneração. ${ }^{2}$

\section{Brasil}

Como os outros países latino-americanos, o Brasil no século XXI também passou a apresentar um maior crescimento econômico comparativamente ao verificado nos anos 1990. A ascensão de um governo em parte crítico ao modelo 
neoliberal permitiu algumas medidas pró-trabalhadores e que sinalizavam uma maior regulação do mercado de trabalho por parte do Estado. Nesse contexto, foi possível impedir o aprofundamento da precarização do trabalho, porém não se conseguiu reverter completamente o retrocesso herdado da década de 1990. Ainda assim essas mudanças tiveram efeitos positivos para o Brasil e refletiram em uma melhoria do mercado de trabalho, o que levou por terra os argumentos neoliberais de que se deveria ampliar a desregulamentação do mercado de trabalho (Manzano; Santos; Teixeira, 2013).

No governo do presidente Luiz Inácio Lula da Silva e no primeiro ano do de Dilma Rousseff, observa-se uma redução da taxa de desemprego contínua, com exceção dos anos 2006 e 2009 em que há um crescimento da taxa de desemprego em 0,2\% (Gráfico 3). Em 2009 esse aumento pode ser explicado pela variação negativa do PIB $(-0,3 \%)$, sendo essa, em boa medida, reflexo da crise econômica mundial. É importante observar que apesar da retração do PIB nesse ano, os efeitos no emprego foram bastante suaves, principalmente pelo sucesso das políticas anticíclicas implementadas pelo governo brasileiro (Krein; Santos; Moretto, 2013).

Da mesma forma, é possível observar que as variações do PIB no período considerado não tiveram grande influência na variação da taxa de desemprego, que manteve a tendência de queda apesar da irregularidade do crescimento econômico. Analisando o Gráfico 1 percebemos também que, até 2009, a tendência de queda na taxa de desemprego segue um ritmo bastante similar ao da média latino-americana, em parte pelo fato de o Brasil ter um grande peso na economia da América Latina. Porém, após 2009, o Brasil passa a ter uma redução do desemprego mais acentuada do que a média.

Gráfico 1 - Taxa de desemprego aberto no Brasil, taxa de desemprego aberto na América Latina e variação do PIB do Brasil entre 2003 e 2012

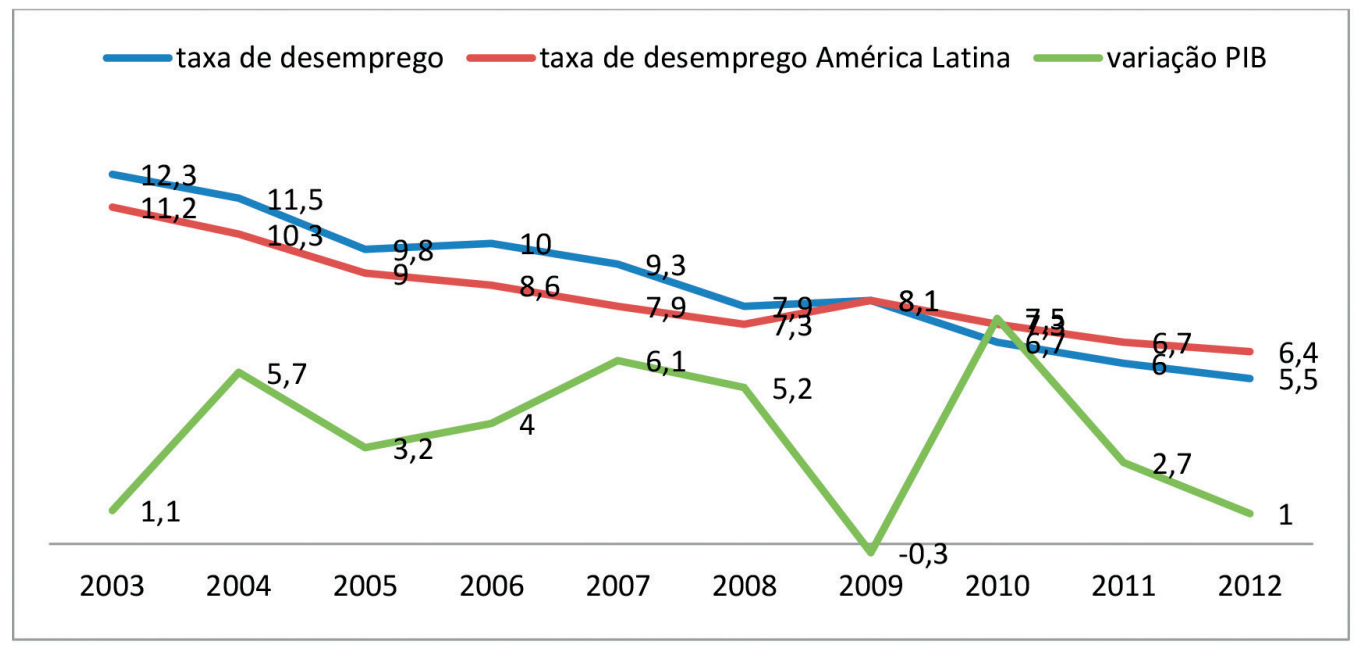

Fonte: Dados obtidos pelos autores a partir de Cepal - Estatísticas Sociais (2014). 
Essa redução do desemprego veio acompanhada de um aumento na formalização dos trabalhadores. Mediante a perspectiva do setor informal, o movimento apresentado no Gráfico 2 deixa evidente a redução da informalidade no século XXI no Brasil. Colocamos o movimento ocorrido entre 1993 e 1999 para mostrar a quebra de uma tendência a partir da virada do século. Já em 2002 o setor informal passa a ter menor importância do que em 1993. A partir de 2001 o único ano que apresenta um crescimento do setor informal é o de 2009, possivelmente por efeitos da crise internacional.

Além da diminuição do desemprego, dos esforços de regulamentação do trabalho e do contexto econômico favorável, Alves e Corsi (2010, p.251) apresentam outros dois fatores que nos ajudam a compreender essa tendência: a formalização de trabalhadores domésticos e o aumento do emprego público (funcionários público estatutário).

Gráfico 2 - Porcentagem de ocupados urbanos em setores de baixa produtividade (setor informal) no Brasil entre 1993 e 2012

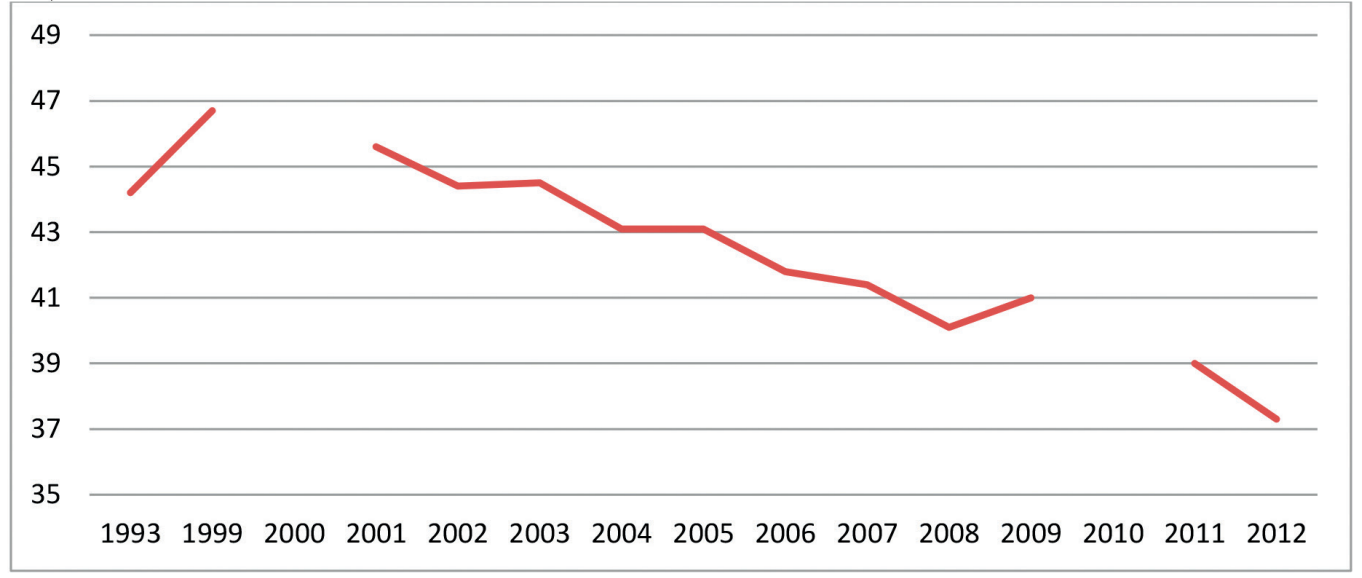

Fonte: Dados obtidos pelos autores a partir de Cepal - Estatísticas Sociais (2014).

Junto com o movimento de melhoria nas taxas de desemprego e na informalidade, também há um cenário positivo com relação às remunerações dos trabalhadores. Há uma valorização contínua e significativa do salário mínimo real no Brasil. Ressalte-se que esse aumento real da remuneração mínima já estava presente no governo FHC e no governo Lula e consegue manter seu valor crescente. Entre 2000 e 2012, o salário mínimo sofre um aumento real de 97,5\%. De 2003 a 2012, o crescimento é de 80 pontos percentuais. Esse aumento se deve, em grande parte, à consolidação da política de valorização do salário mínimo, fruto de um esforço conjunto dos sindicatos com o governo. Para Krein, Santos e Moretto (2013, p.35), além disso, a valorização do salário mínimo foi fundamental para

[...] elevar os rendimentos do trabalho de ocupações precárias, cujo processo de melhoria da qualidade, entre vários aspectos, significou a ampliação 
de rendimentos indiretos, como o décimo-terceiro salário, o FGTS, 1/3 de férias, seguro-desemprego, auxílios (acidentes, doenças), $14^{\circ}$ salário (PIS) e outros.

O comportamento da remuneração média se diferencia do comportamento do salário mínimo. Há uma desvalorização do salário médio de 1999 até 2003. Entretanto, a partir de 2004 o salário médio passa a apresentar uma tendência de alta, sofrendo valorizações reais ano a ano. Apesar disso, é apenas em 2012 que o salário médio volta a se equiparar ao valor do ano 2000.

É importante ressaltar ainda que a política de valorização do salário mínimo refletiu no bom desempenho do salário médio, uma vez que colabora para elevar a média dos salários. Sendo assim, pós 2003 (governo Lula), os aumentos do salário mínimo bastante significativos permitiram o crescimento do salário médio, o que não havia ocorrido entre 1999 e 2003. Além disso, tanto com relação ao salário mínimo como com relação ao médio, o contexto de estabilidade com inflação baixa permitiu que os salários se mantivessem valorizados. Os indicadores observados anteriormente, como a taxa de desemprego declinante e o aumento da formalidade, também impactaram positivamente nos salários.

Esse movimento de valorização dos salários fez que se expandisse a parcela do rendimento do trabalho na renda brasileira, porém, "ao final da década de 2000, o rendimento do trabalho ainda não alcançou a mesma participação na renda nacional que tinha 1990, 45,4\%" (Alves; Corsi, 2010, p.253).

Gráfico 3 - Índice do salário médio real no Brasil entre 1999 e 2012 (índice anual médio, 2000=100)

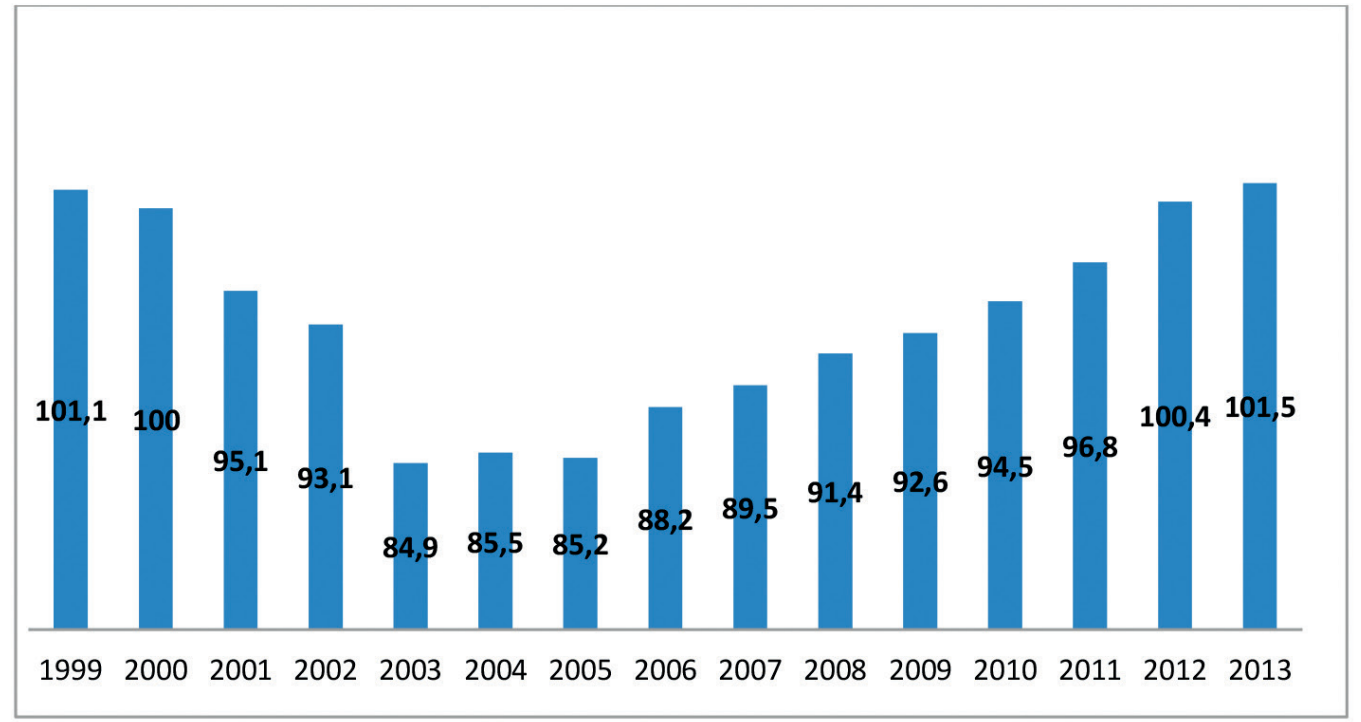

Fonte: Dados obtidos pelos autores a partir de Cepal - Estatísticas Sociais (2014). 
Após analisar os indicadores nesta seção fica bastante evidente a melhora significativa do mercado de trabalho do Brasil neste início de século. Como explicado inicialmente, o contexto econômico favorável somado a políticas pró-trabalhadores teve impactos positivos. Assim, foi possível em parte barrar o avanço da precarização do trabalho vinda do período neoliberal.

\section{Colômbia}

Ao longo dos anos 1990 a Colômbia acompanhou o processo de flexibilização do trabalho e desregulamentação do mercado de trabalho que ocorreu na América Latina. O governo eleito em 2002, do presidente Álvaro Uribe, não se apresentava como crítico a esse modelo neoliberal. Pelo contrário, o novo governo considerava as normas trabalhistas demasiado rígidas e assim buscava aprofundar o processo iniciado na década anterior.

Uma das primeiras medidas desse novo governo foi a Reforma Laboral ainda em 2002 (Lei n.789/2002), quando o número de desempregados no país atingia quase um quinto da população economicamente ativa (18,2\% em 2001). A Reforma ampliava as formas de contratação (temporários, de tempo parcial, de aprendizagem), aumentava a jornada de trabalho diurna, diminuía o valor das horas extras dominicais e de feriados e reduzia, para os empregadores, os custos de demissão dos funcionários (Elicabide, 2013; Torres, 2011).

A política trabalhista do governo de Álvaro Uribe (2002-2010) estava centrada no crescimento econômico, pois o governo acreditava que os problemas de desemprego além do alto grau de informalidade se resolveriam via mercado, desde que houvesse um bom desempenho econômico do país (Torres, 2011).

Analisando a taxa de desemprego da Colômbia, vemos que ela apresenta tendência de queda no governo Álvaro Uribe. É importante ressaltar que a segunda menor taxa de desemprego ocorre justamente no auge do crescimento econômico do período, em 2007, quando a taxa de variação do PIB é de 6,9\% e a taxa de desemprego é de $11,4 \%$. Já quando o PIB volta a patamares mais baixos de crescimento, com uma taxa de $1,7 \%$, o desemprego volta a crescer, alcançando $13 \%$ em 2009. É possível observar que a variação da taxa de desemprego esteve muito ligada às variações do PIB, sintoma de políticas trabalhistas marginais e submetidas ao desempenho econômico (Torres, 2011).

Na comparação entre as tendências da taxa de desemprego média da América Latina e a taxa de desemprego colombiana, se observa que até 2007 a queda do desemprego era mais acentuada na Colômbia vis-à-vis a média dos países latino-americanos. Entretanto, a partir de 2007, há uma desaceleração da queda da taxa de desemprego colombiana até 2009 , quando se estabiliza, em um comportamento bastante similar ao da média latino-americana. 
Gráfico 4 - Taxa de desemprego aberto na Colômbia, taxa de desemprego aberto na América Latina e variação do PIB da Colômbia entre 2003 e 2012

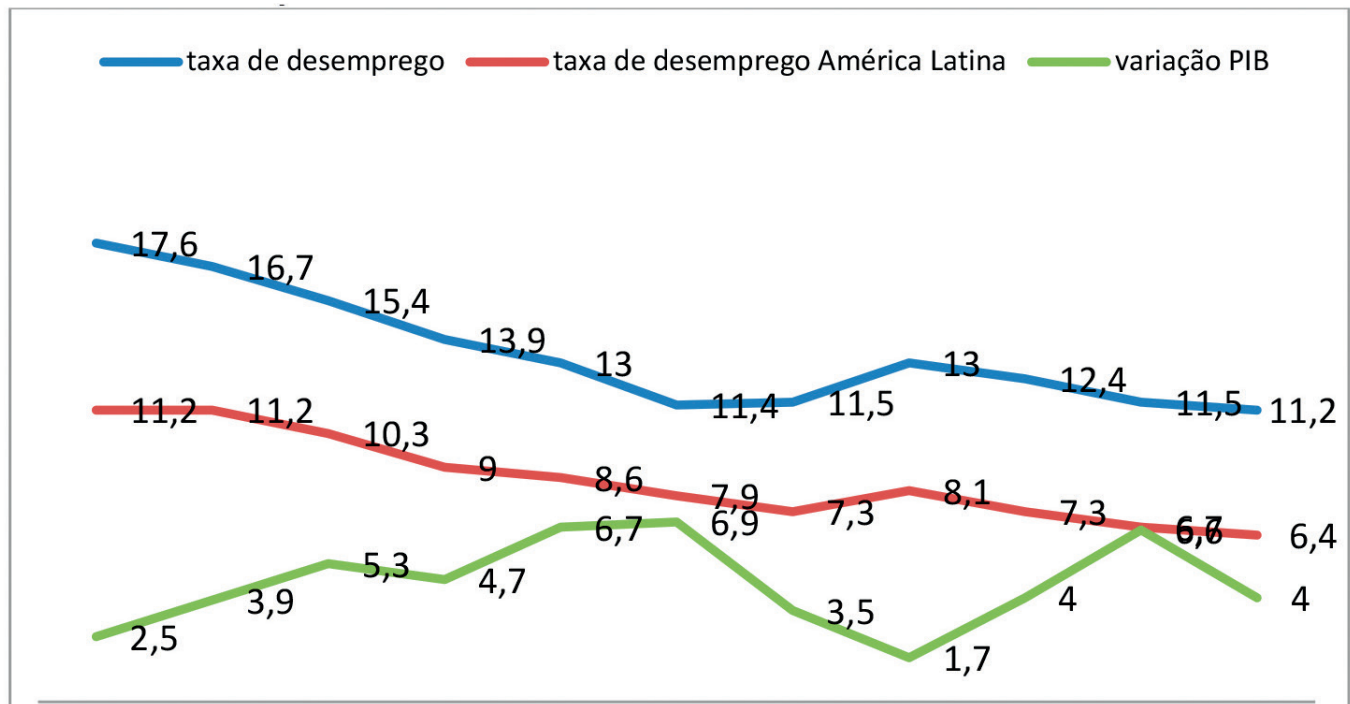

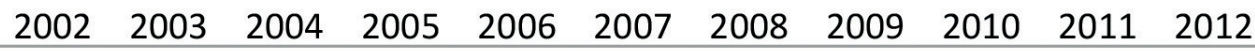

Fonte: Dados obtidos pelos autores a partir de Cepal - Estatísticas sociais (2014).

Os dados sobre informalidade ficaram aquém do esperado pelo governo Uribe. Ao implantar a Reforma Laboral, o governo argumentava que uma maior flexibilização da legislação trabalhista iria influenciar positivamente na geração de empregos formais. Entretanto os dados não apontaram avanços significativos após 2002.

Sobre os trabalhadores do setor informal, os dados completos só estão disponíveis após 2008, pois houve modificação nos critérios com relação à microempresas, tornando a série não comparável. Assim, no Gráfico 5 utilizamos duas séries: a mais longa representa apenas parte do setor informal, pois não considera os trabalhadores em microempresas; já a menor que inicia a partir de 2008 segue a definição completa de setor informal referida anteriormente. Como o nosso estudo tem como foco compreender os movimentos no mercado de trabalho, consideraremos o indicador que apresenta parte do setor informal para observar o movimento da formalização, considerando que nos anos que temos o setor informal completo ambos apresentam as mesmas tendências.

Dessa forma, se observa um aumento do setor informal entre 1991 e 2002 e, a partir de 2003, uma queda até o ano 2005, quando volta a apresentar crescimento até 2011. Vale ressaltar que em 2006 e em 2007 o PIB da Colômbia estava tendo crescimento expressivo (6,7 e 6,9 , respectivamente), mas isso não se refletiu em aumento relativo do setor formal. Quando analisada a série completa do setor informal, observamos que em quatro desses anos, entre 2008 e 2012 , não houve variações significativas. Além disso, no período, o setor infor- 
mal representou quase $60 \%$ dos ocupados na Colômbia, ou seja, mais da metade dos trabalhadores estavam em ocupações consideradas precárias.

Gráfico 5 - Porcentagem de ocupados urbanos em setores de baixa produtividade (setor informal) na Colômbia entre 1991 e 2012

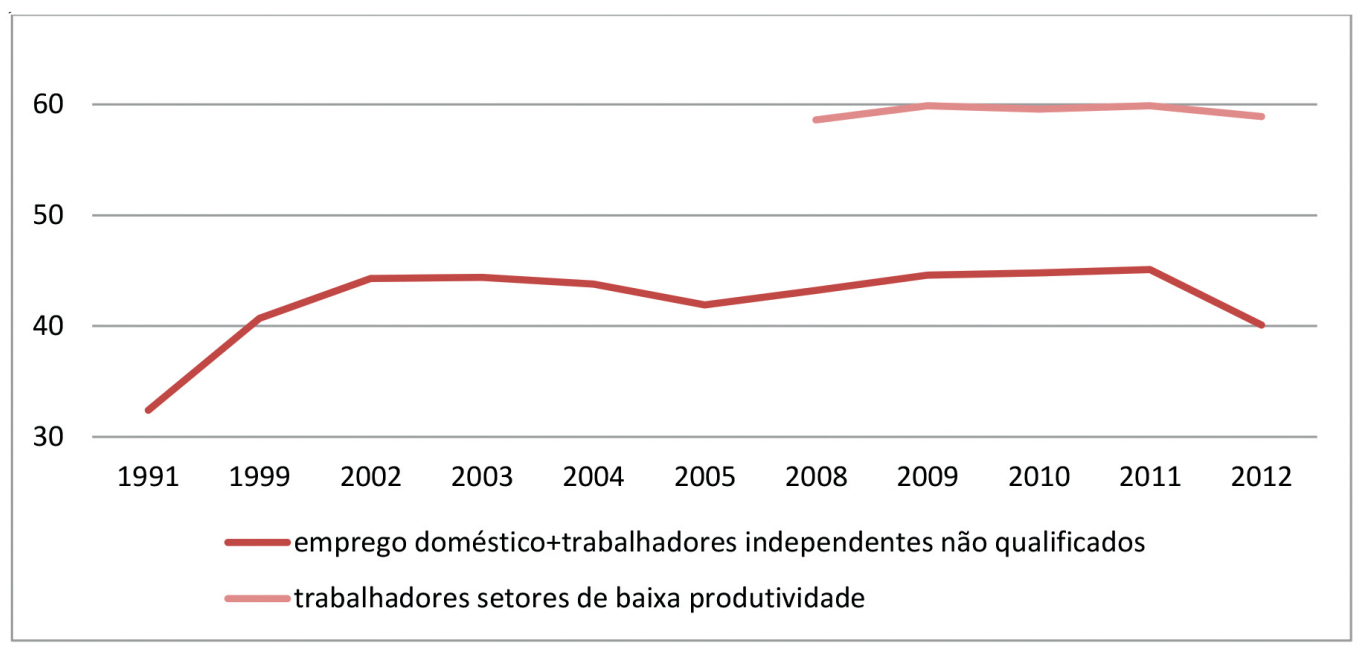

Fonte: Dados obtidos pelos autores a partir de Cepal - Estatísticas sociais (2014).

Podemos concluir então que Álvaro Uribe deixa o governo em 2010 com uma situação pior com relação à informalidade do que quando assume a presidência em 2002. Fato esse que nos leva a crer que a maior flexibilização e desregulamentação do mercado de trabalho teve impactos negativos na tentativa de aumentar relativamente o emprego formal, mesmo em um cenário de crescimento econômico e de redução do desemprego que deveria ser favorável.

Com relação ao salário mínimo, com exceção ao ano 2008, em todos os outros houve valorização real, ou seja, a remuneração subiu acima da inflação. Além disso, não é possível notar nenhuma mudança na tendência após a Reforma Laboral de 2002. Apesar de valorizações contínuas, o aumento real foi baixo, entre 2000 e 2012 , de apenas $14,2 \%$.

Já o salário médio, apesar de também apresentar uma tendência crescente, teve maior irregularidade apresentando desvalorizações reais em 2001, 2003, 2007, 2008 e 2012. O que se pode concluir é que não há uma mudança significativa na variação tanto dos salários médios reais quanto do salário mínimo real após a Reforma Laboral de 2002, mostrando uma continuidade de projeto em relação à política salarial. 
Gráfico 6 - Índice do salário médio real na Colômbia entre 1999 e 2012 (índice anual médio, $2000=100$ )

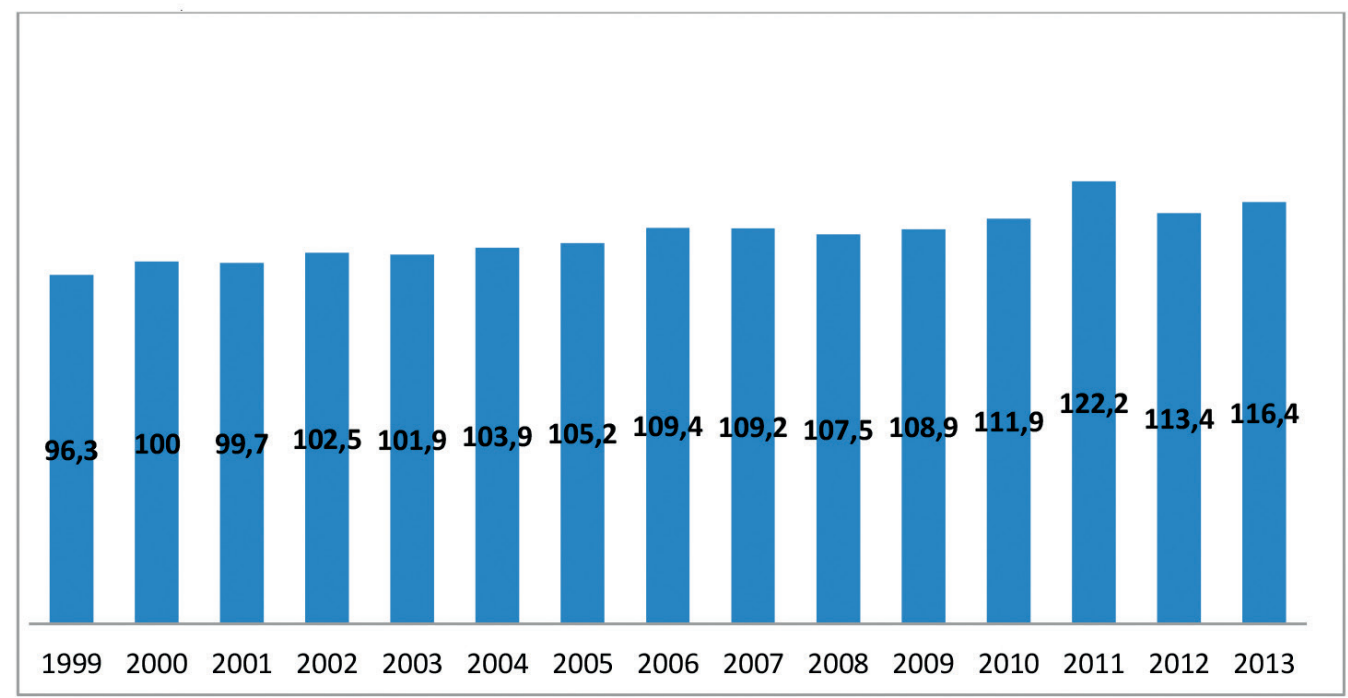

Fonte: Dados obtidos pelos autores a partir de Cepal - Estatísticas sociais (2014).

Os dados sobre o mercado de trabalho observados nesta seção mostram movimentos distintos. Embora, o desemprego tenha apresentado um melhor comportamento a partir da virada do século com relação à década de 1990 , isso não se refletiu na diminuição relativa da informalidade que, pelo contrário, continuou aumentando no período. A valorização do salário médio foi pequena acompanhando a valorização do salário mínimo. Assim, não se observa mudanças significativas após a Reforma Laboral.

\section{Venezuela}

A Venezuela buscou uma ruptura efetiva com o modelo neoliberal e objetivou a construção de uma nova sociedade. O governo Chávez teve como horizonte implementar o socialismo do século XXI no país. Entretanto, no que concerne ao mercado de trabalho, apesar de mudanças significativas com relação aos anos 1990, não houve um novo marco regulatório adaptado a essa transição ao socialismo (Lucena, 2010).

A situação do mercado de trabalho na Venezuela precisa ser analisada considerando uma questão central: apesar dos esforços para romper com as políticas neoliberais, as políticas do governo de Hugo Chávez, com relação ao emprego, não foram voltadas aos trabalhadores assalariados. Isso porque "el empleo subordinado es concebido como una rémora del pasado que impide el verdadero desarrollo de las potencialidades humanas, adquiriendo el trabajo autónomo una nueva valoración" (Iranzo; Richter, 2006). O que observamos na Venezuela é uma nova lógica com relação ao trabalho. Ou seja, não é apenas o nível de emprego ou salário que está no centro da preocupação do governo, e sim uma forma que reduza a exploração do trabalhador. Nessa concepção, o Estado exerce um papel 
central nessa forma de organização do trabalho, tanto como fomentador quanto como empregador.

Para Lucena (2008) e Iranzo e Richter (2006), no governo Chávez uma nova forma de organização produtiva estava sendo buscada, onde a prioridade são as formas de propriedades sociais que visem construir um Modelo Produtivo Socialista. Assim, o governo venezuelano fomentou o cooperativismo e o trabalho associado, além da formação de microempresários. Essa visão já está presente desde o princípio do governo, mas é em 2002 que, deliberadamente, há uma política laboral neste sentido. Iranzo e Richter $(2006$, p.9) resumem as estratégias centrais para a ocupação,

a) la conservación de los puestos existentes a través de decretos ejecutivos que probiben el despido sin autorización previa de la inspectoria del trabajo (inamovilidad laboral); b) la promoción del trabajo informal y de los microempresarios; c) la promoción de cooperativas de trabajo asociado y la creación de las misiones como forma de redistribución del ingreso en sustitución a la creación de puestos de trabajo productivos.

Com relação ao primeiro item, a proibição das demissões sem justa causa teve inicialmente um resultado positivo, porém, ao longo do tempo, gerou um aumento das subcontratações e das contratações temporais. A promoção do setor informal ocorreu mediante uma série de incentivos ao microcrédito por parte do governo. Junto a isso, o governo passou a fazer vista grossa em relação aos trabalhadores não regularizados que trabalhavam na informalidade (Iranzo, 2011 ). A criação das “misiones”, citada acima, se refere ao programa do governo "Misiones Vuelvan Caras" que tinham como objetivo, por meio de cursos preparatórios para trabalhadores, ajudar a estabelecer uma nova economia, incentivando a economia solidária e a economia popular.

Ao mesmo tempo, essa centralização no Estado acabou tentando tirar a autonomia do movimento sindical que teve diversos conflitos com o governo Chávez. Para Iranzo (2011, p.33), houve uma mudança da lógica do capital para a lógica do Estado, que não dá espaço aos atores sociais que não concordam com as políticas do governo. Para ela "en ninguno de los dos casos ha existido el ejercicio de una democracia asentada sobre la negociación y el respeto de los diferentes intereses que componen la sociedade". Enquanto não se alcança o objetivo socialista, os trabalhadores que continuam inseridos em uma lógica capitalista acabam por ser prejudicados, deixando o sindicalismo marginalizado.

Com relação aos movimentos da taxa de desemprego, podemos notar uma queda substancial do desemprego principalmente após 2003. Nesse período, a taxa de desemprego venezuelana que era bastante superior à taxa média latino-americana se aproxima desta última. Ou seja, a intensidade da diminuição do desemprego na Venezuela é maior do que a média dos países da América Latina.

Comparando o movimento da taxa de desemprego e a variação do PIB verificamos que a taxa de desemprego apresenta um aumento em 2002 e 2003, 
anos em que a variação do PIB é negativa em 8,9\% e 7,8\%, respectivamente. Porém, após 2003, o movimento de redução da taxa de desemprego parece ser continuo apesar das variações do PIB. Vale ressaltar que o crescimento impressionante de 2003 para 2004 está relacionado ao aumento expressivo do preço do petróleo.

Assim, a queda sustentada do desemprego ocorre após essa nova estratégia de manutenção e geração de emprego explicitada por Iranzo e Richter (2006). Em nove anos (entre 2003 e 2012), a taxa de desemprego reduz 10 pontos percentuais.

Gráfico 7 - Taxa de desemprego aberto na Venezuela, taxa de desemprego aberto na América Latina e variação do PIB da Venezuela entre 2003 e 2012

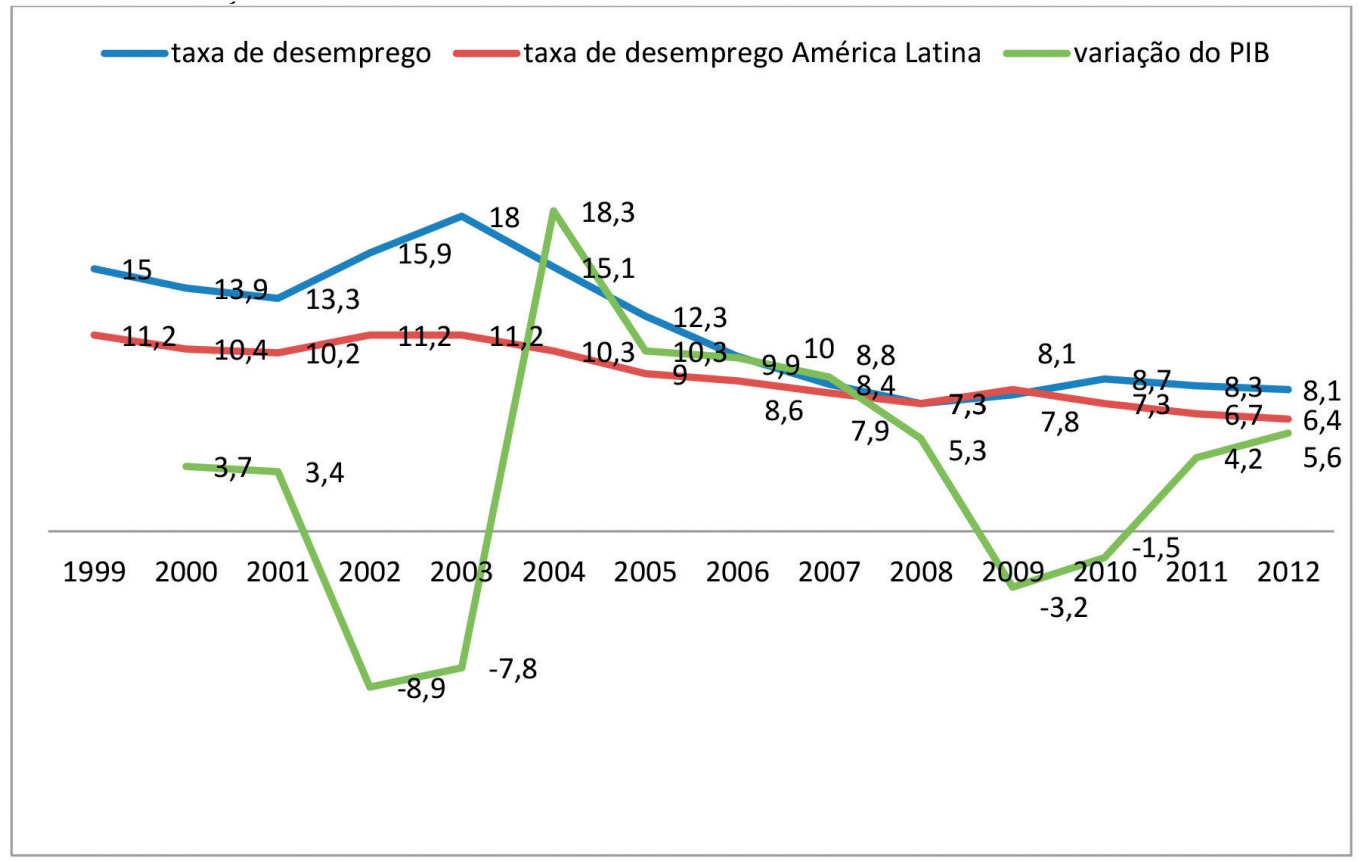

Fonte: Dados obtidos pela autora a partir de Cepal - Estatísticas sociais (2014).

Para analisar o emprego informal na Venezuela é preciso observar a visão do governo de que o setor informal não é algo negativo. Na lógica inversa da Colômbia e do Brasil que buscam reduzir o emprego informal, o governo venezuelano incentivou os trabalhadores até mesmo a saírem de empregos formais. Dessa forma, não há políticas visando essa superação, pelo contrário, o governo busca incentivar os trabalhadores que estão à margem do processo de produção (Lucena, 2010).

Notamos que no período neoliberal, entre 1992 e 1999, há um aumento substancial do setor informal e, após a eleição de Chávez, essa tendência de crescimento se mantém até 2002. Apesar da redução do setor informal, em 2012 ele representava metade da população ocupada, estando apenas um pouco abaixo 
da porcentagem de 1999. Assim, o que percebemos na análise dos gráficos do período Chávez foi uma leve tendência de queda da ocupação informal, apesar de movimentos contraditórios de aumento e redução.

Gráfico 8 - Porcentagem de ocupados urbanos em setores de baixa produtividade (setor informal) na Venezuela entre 1992 e 2012

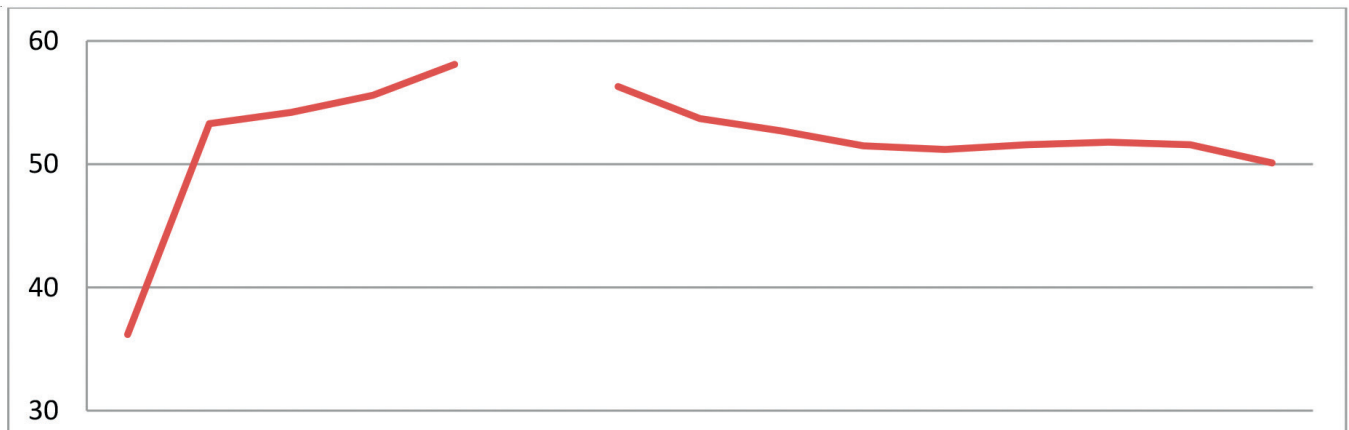

199219992000200120022003200420052006200720082009201020112012

Fonte: Dados obtidos pelos autores a partir de Cepal - Estatísticas sociais (2014).

Os salários apresentaram o pior comportamento entre os indicadores analisados para a Venezuela. Mesmo com os aumentos nominais do salário mínimo na Venezuela a inflação corroeu o salário real. Como os ajustes são anuais por mais que a política do governo seja corrigir o salário mínimo acima da inflação, ao longo do ano os salários vão perdendo seu valor real.

Houve um período de valorização do salário, entre 2003 e 2006, porém a partir de 2007 o salário mínimo tem uma desvalorização real, chegando em 2011 com um poder de compra inferior ao de 1999. A definição de como deveria ser determinado salário mínimo na Venezuela passou por controvérsias no período do governo Chávez. Legalmente, o seu valor deveria ser negociado entre empregadores e trabalhadores e, em um segundo momento, passado ao executivo que podia aprovar ou fazer modificações. Entretanto, a partir de 1999, foram chamadas outras instituições para a negociação, o que gerou um confronto com os representantes tradicionais dos sindicatos e das empresas, " $a$ tal punto que denunciaron el problema ante la OIT por considerar que ello implicaba la deformación y ruptura del diálogo social" (Lucena, 2010, p.408). Após esses conflitos dos representantes dos empresários e dos sindicatos com o governo, ficou estabelecido que o salário mínimo seria determinado pelo governo (ibidem).

Entre 2003 e 2012 a remuneração média e o salário mínimo tiverem um movimento muito parecido, embora as variações do salário médio real tivessem sido maiores. É possível perceber também uma grande diminuição do salário médio real entre 2001 e 2003. Assim como o salário mínimo, o valor do salário 
médio igualmente foi corroído pela alta inflação, de modo que, de uma maneira geral, a partir de 2001 ele sofre decréscimos significativos atingindo o menor valor real no ano de 2010.

Gráfico 9 - Índice do salário médio real na Venezuela entre 1999 e 2012 (índice anual médio, $2000=100$ )

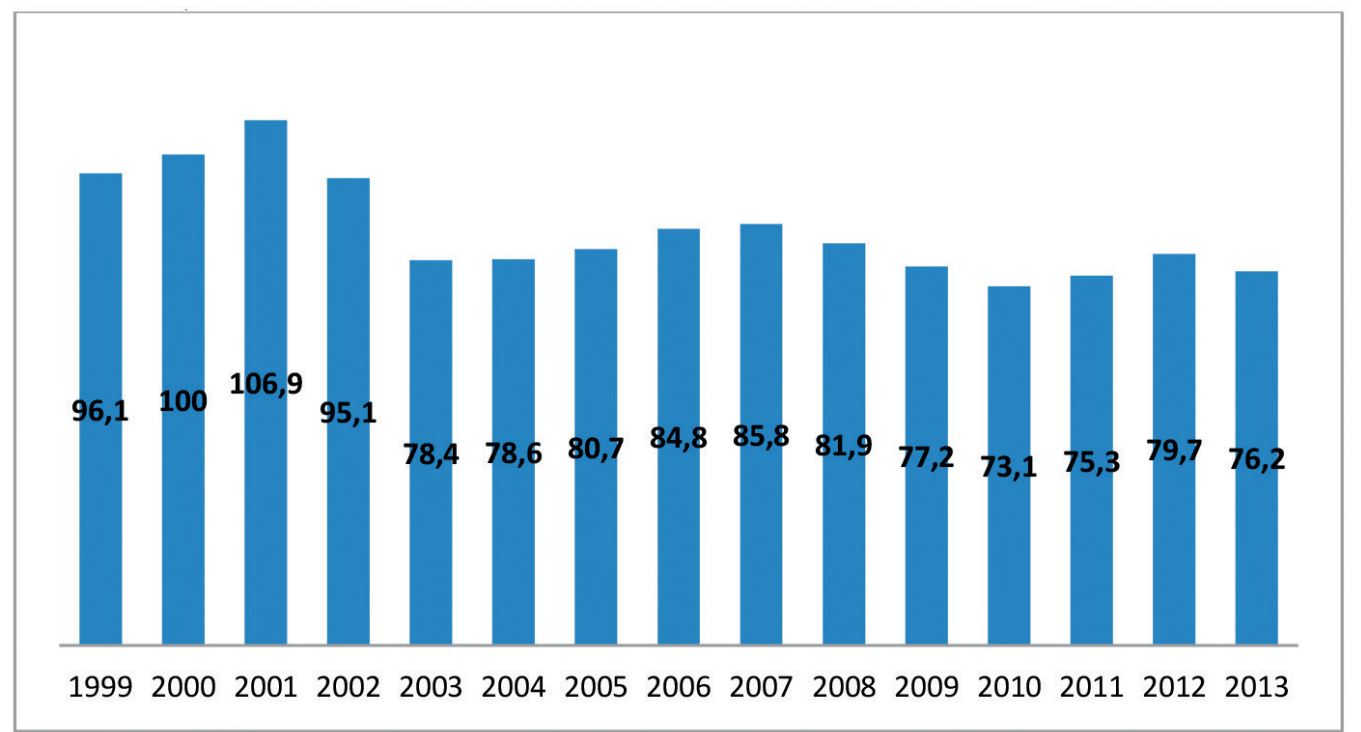

Fonte: Dados obtidos pelos autores a partir de Cepal - Estatísticas sociais (2014).

Pelo exposto anteriormente, ficou clara a deterioração das remunerações dos trabalhadores no período do governo Chávez. E também que a redução do valor real do salário médio foi superior à do salário mínimo. No final da série analisada, em 2012, o salário mínimo se aproxima do valor real que tinha em 1999, enquanto o salário médio se reduziu significativamente.

Com relação aos indicadores analisados, podemos então concluir que na Venezuela houve uma redução significativa das taxas de desemprego, com a informalidade apresentando variações, apesar de uma pequena tendência de queda, algo que em parte mostra que os incentivos governamentais não surtiram os impactos desejados. Já os salários reais caíram. Isso fica mais nítido em relação ao salário médio, já que o mínimo apresentou uma elevação no meio do período, entre 2005 e 2009, voltando a cair daí em diante. Segundo Lucena (2010, p.247)

En once años de transformaciones diversas em el modelo productivo aún no se há logrado consolidar un sistema productivo alternativo al tradicional. La transición al socialismo muestra una gradual estatización de entidades productivas, pero con muy limitados resultados tanto en lo productivo como en alcanzar estadios más avanzados de convivencia entre los trabajadores, en sus diversos segmentos, y en la relación con las comunidades y con los entes estatales. 


\section{Analisando a concentração de renda}

Comparando os três países analisados, observamos que há diferenças claras nas medidas de política econômica voltadas ao mercado de trabalho. Elas expressam diferentes visões de desenvolvimento. Diferentemente dos anos 1990 quando havia quase consenso com relação à implementação do modelo neoliberal, nos anos 2000 alguns países questionaram a flexibilização e a desregulamentação do mercado de trabalho o que em boa medida, representou um avanço para os trabalhadores. Essa mudança de objetivos impactou diretamente na vida dos trabalhadores.

As melhorias no mercado de trabalho, em conjunto com outras políticas sociais dos governos, refletiram na queda da desigualdade de renda. Na América Latina, a média do índice de Gini passou de 0,547 em 2002 para 0,496 em 2012. Também para os três países analisados há redução desse indicador (Tabela 1). A queda mais expressiva do índice de Gini ocorreu na Venezuela, seguida pelo Brasil. Não por acaso, ambos os países tiveram as maiores reduções do desemprego, além de apresentarem uma melhor performance do salário mínimo comparativamente ao do salário médio.

Tabela 1 - Índice de Gini no Brasil, na Colômbia, Venezuela e a média simples da América Latina entre 2002 e 2012

\begin{tabular}{c|c|c}
\hline Países & 2002 & 2012 \\
\hline Brasil & 0,634 & 0,567 \\
\hline Colômbia & 0,567 & 0,536 \\
\hline Venezuela & 0,500 & 0,405 \\
\hline América Latina & 0,547 & 0,496 \\
\hline
\end{tabular}

Fonte: Dados obtidos pelos autores a partir de Cepal - Estatísticas sociais (2014).

Além disso, analisando a distribuição percentual da renda, também se percebe o aumento do percentual da renda dos $20 \%$ mais pobres e a diminuição do mesmo indicador para os $20 \%$ mais ricos. Isso pode ser visualizado nos três países estudados como mostra a Tabela 2.

Observamos assim que mesmo o país que seguiu o receituário neoliberal teve melhoras nas taxas de desemprego e nos salários, além da queda das desigualdades de renda. Dessa forma, concluímos que esse resultado, em parte, também foi fruto de um cenário macroeconômico favorável, devido ao crescimento da economia mundial, até 2007 , e, depois disso, à relativamente boa recuperação das economias em desenvolvimento. 
Tabela 2 - Distribuição percentual da renda (20\% mais ricos e $20 \%$ mais pobres) no Brasil, na Colômbia e na Venezuela entre 2001 e 2009

\begin{tabular}{l|c|c}
\hline & $20 \%$ mais pobres & $20 \%$ mais ricos \\
\hline Brasil & & \\
\hline 2001 & 2,07 & 63,93 \\
\hline 2012 & 3,00 & 60,08 \\
\hline Colômbia & & \\
\hline 2001 & 2,02 & 61,34 \\
\hline 2012 & 3,20 & 58,00 \\
\hline Venezuela & & 51,97 \\
\hline 2001 & 3,97 & 46,00 \\
\hline 2012 & 5,20 & \\
\hline
\end{tabular}

Fonte: Dados obtidos pelos autores a partir de Cepal - Estatísticas sociais (2014).

\section{Considerações finais}

Observamos que as diferentes vias de desenvolvimento impactaram no mercado de trabalho de forma distinta. Um maior afastamento das políticas neoliberais, como houve no Brasil em relação à Colômbia, fez que o primeiro gerasse melhores resultados para os trabalhadores. Entre os governos críticos ao modelo vigente nos anos 1990 encontramos diferenças no grau de afastamento das políticas do período. A Venezuela implementou mudanças muito mais profundas que o Brasil, algumas bem-sucedidas, outras nem tanto, buscando uma transição para um modelo socialista. Por um lado, conseguiu se afastar do neoliberalismo, por outro, o centralismo do papel do Estado trouxe falta de autonomia aos trabalhadores, renegando o papel do movimento sindical, ao mesmo tempo em que realizou poucas políticas para os trabalhadores assalariados.

Acreditamos que o Brasil, ao buscar barrar as políticas neoliberais e realizar políticas pró-trabalhadores, obteve resultados mais significativos na melhora do mercado de trabalho. Já a Venezuela passou pelas mudanças políticas mais profundas, realmente negando a doutrina neoliberal e, em boa medida, o próprio capitalismo. Entretanto, poucas políticas foram voltadas para os trabalhadores assalariados e ao mesmo tempo houve uma tentativa de enfraquecer o movimento sindical, talvez em parte por não ser considerado necessário em uma sociedade socialista (Iranzo, 2011).

Em nossa visão, o Brasil conseguiu atingir de forma mais eficaz a melhora do mercado de trabalho, devido à ação do governo, em certa medida pró-trabalhadores, regulamentando esse mercado e barrando sua flexibilização. Por outro 
lado, a Reforma Laboral na Colômbia aprofundou o processo de flexibilização e desregulamentação do trabalho iniciado nos anos 1990. Já a Venezuela buscou caminhar em direção ao "socialismo do século XXI" o que fez que o governo criasse medidas com o intuito de constituir um novo modelo de produção, mas a forte intervenção do Estado nas relações de trabalho acabou por, em parte, desestruturar a luta trabalhista no país.

Houve uma tendência de queda do desemprego nos três países estudados. Observamos também que na Colômbia os movimentos do emprego estiveram mais ligados ao desempenho econômico, enquanto no Brasil e na Venezuela manteve-se a tendência de queda, mesmo em anos de redução do crescimento do PIB. Vale observar também a intensidade das reduções, enquanto a Venezuela tinha a taxa de desemprego similar à colombiana em 2003, o país conseguiu reduzir a um dígito já em 2006, algo que a Colômbia não conseguiu em todo o período analisado.

Quanto à informalidade, o Brasil apresentou os dados mais significativos reduzindo substancialmente a participação dessa relação de trabalho no total dos ocupados. Já na Colômbia a redução da informalidade não foi sustentada, uma vez que mostrou valores similares no início e no fim do período analisado, apesar de algumas variações nos anos intermediários. A Venezuela é um caso a parte com relação à informalidade, pois é algo visto como positivo, com uma nova perspectiva com relação ao trabalho. Mesmo assim, houve queda do setor informal.

Com relação aos salários, a Venezuela apresentou o pior desempenho, o que pode ser explicado pelo aprofundamento do processo inflacionário. Com isso, as valorizações nominais, apesar de altas, não foram suficientes para impedir a queda nos valores reais dos salários, tanto o do mínimo quanto o do médio.

Averiguamos que o cenário externo favorável às economias latino-americanas, gerando dinamismo interno, trouxe efeitos positivos com relação à redução do desemprego de todos os países analisados. Entretanto, acreditamos que o fim da crença na desregulamentação e na flexibilização do mercado de trabalho em alguns países também colaboraram para melhorias. Sabemos que não foi possível abordar todas as especificidades de cada país que podem ter tido influência no mercado de trabalho, porém buscamos relacionar o desempenho desse mercado com as decisões de políticas econômicas e trabalhistas mais importantes na nossa visão.

Os impactos do neoliberalismo para os trabalhadores nos países latino-americanos são profundos e difíceis de ser revertidos. A precarização do trabalho continua sendo um grande problema, dado que o contexto de globalização e financeirização do capital se mantém. Pretendemos com este estudo contribuir para a compreensão das alternativas que estão postas com relação à trajetória de desenvolvimento desses países. Dessa forma, acreditamos que uma recuperação das condições de emprego é decisiva para se pensar o futuro e a melhoria da qualidade de vida nos países da América Latina. 
1 Neste trabalho, analisaremos o "setor informal" que se refere às características das unidades de produção. Neste caso, são considerados parte do setor informal os trabalhadores urbanos de setores de baixa produtividade, sejam eles empregadores ou assalariados que trabalham em microempresas (até cinco empregados), pessoas que trabalham em emprego doméstico, sejam ainda trabalhadores independentes não qualificado (sem qualificação profissional ou técnica) (Cepal, 2014).

2 Os dados foram obtidos no site da Cepal (2014), que para chegar aos salários reais deflacionou os valores nominais pelo índice de preços ao consumidor de cada país tanto o salário mínimo como o salário médio nominal. Registre-se ainda que na Colômbia e na Venezuela o IPC é desagregado por estrato de renda, nestes casos se utilizou o deflator do estrato de menor rendimento.

\section{Referências}

ALVES, G.; CORSI, F. L. Precarização do trabalho e nova precariedade salarial no Brasil na década de 2000. Da tessitura da redundância à intermitência da contingência salarial. In: TOLEDO, E. de la G.; NEFFA, J. C. Trabajo y modelos pnoductivos em America Latina: Argentina, Brasil, Colômbia, México y Venezuela luego de la crisis del modo de desarrollo neoliberal. Buenos Aires: Clacso, 2010.

COMISSÃO ECONÔMICA PARA AMÉRICA LATINA E CARIBE - CEPAL. Estatísticas sociais. Santiago: Cepal, 2014.

ELICABIDE, L. C. M. Transformaciones en las relaciones laborales Colômbia y Brasil: Entre la flexibilización y la Regulación. In: CONGRESSO LATINO-AMERICANO DE ESTUdOS DO TRABALHO, 2013, São Paulo. Anais... São Paulo, 2013.

IGLECIAS, W.; CARDOSO, E. W.; STREICH, R. N. Estratégias de desenvolvimento em questão: o debate sobre o papel do Estado no Brasil, México e República Bolivariana da Venezuela, 1989-2010. In: PRIMEIRAS JORNADAS DE PLANEJAMENTO ECONOMMICO E SOCIAL. Instituto Latino-Americano e do Caribe de Planejamento Econômico e Social (ILPES). Santiago: Nações Unidas, 2014.

IRANZO, C. Chávez y la política laboral en Venezuela. Revista Trabajo, Cidade do México, n.6836, p.5-38, 2011.

IRANZO, C.; RICHTER, J. La política laboral en la Venezuela de Hugo Chávez Fríes. Revista Latinoamericano de Estudios del Trabajo, v.11, n.18, 2006.

KREIN, J. D.; SANTOS, A. L. dos; MORETTO, A. Trabalho no Brasil: evolução recente e desafios. Revista Paranaense de Desenvolvimento, Curitiba, v.34, n.124, p.27$53,2013$.

LUCENA, H. Reestructuración productiva en Venezuela: balance laboral. In: TOLEDO, E. de la G.; NEFFA, J. C. Trabajo y modelos pnoductivos em America Latina: Argentina, Brasil, Colômbia, México y Venezuela luego de la crisis del modo de desarrollo neoliberal. Buenos Aires: Clacso, 2010.

MANZANO, M.; SANTOS, A. L. dos; TEIXEIRA, M. Desenvolvimento econômico e trabalho nos anos recentes. In: KREIN, J. D. et al. Regulação do trabalho e instituições públicas. São Paulo: Editora Fundação Perseu Abramo, 2013. 
TOLEDO, E. de la G.; NEFFA, J. C. (Coord.) Trabajo y modelos pnoductivos en America Latina: Argentina, Brasil, Colômbia, México y Venezuela luego de la crisis del modo de desarrollo neoliberal. Buenos Aires: Clacso, 2010.

TORRES, R. M. S. Política Pública Laboral del gobierno de Álvaro Uribe, 2002-2010. Revista Latino-Americana de Estudos do Trabalho, v.16, n.26, 2011.

RESUMO - No início do século XXI houve um melhora nos indicadores do mercado de trabalho da América Latina em comparação aos anos 1990. Neste artigo pretendemos verificar em que medida é possível vincular esses resultados à manutenção ou à reorientação da política econômica. Para tanto, escolhemos três países, Venezuela, Brasil e Colômbia, que acreditamos tenham praticado, nesse começo de século, distintas estratégias de desenvolvimento econômico.

PALAVRA-CHAVE: Mercado de trabalho, Taxa de desemprego, Informalidade, Salários, Políticas neoliberais, América Latina.

ABSTRACT - In the early $21^{\text {st }}$ century, there was a general improvement of the labor market indicators in Latin America compared to the 1990s. In this paper, we intend to examine to what extent it is possible to associate these improved results with the maintenance or reorientation of economic policy. Toward this end, we chose three countries - Venezuela, Brazil and Colombia - that, in our view, have put into place different economic development strategies in the beginning of the new century.

KEYWORDS: Labor market, Unemployment rates, Informal economy, Wages, Neoliberal policies, Latin America.

Mariana Hansen Garcia é bacharel em Ciências Econômicas pela UFRGS e bacharel em Comunicação Social pela PUC-RS. @ - marianagarcia.h.g@gmail.com

Cássio da Silva Calvete é doutor em Economia Social e do Trabalho pela Unicamp e professor adjunto da UFRGS. @ - cassio.calvete@ufrgs.br

Recebido em 9.9.2015 e aceito em 18.9.2015.

I Pontifícia Universidade Católica Rio Grande do Sul, Porto Alegre/Rio Grande do Sul, Brasil.

II Universidade Estadual de Campinas, Campinas/São Paulo, Brasil. 
